University of Nebraska - Lincoln

DigitalCommons@University of Nebraska - Lincoln

Center for Brain, Biology and Behavior: Papers \&

Publications

Brain, Biology and Behavior, Center for

$9-2020$

\title{
Validating Tackle Mechanics in American Football: Improving Safety and Performance
}

Arthur C. Maerlender

Caitlin J. Masterson

Rex Norris

Adam Hinthorne

Follow this and additional works at: https://digitalcommons.unl.edu/cbbbpapers

Part of the Behavior and Behavior Mechanisms Commons, Nervous System Commons, Other Analytical, Diagnostic and Therapeutic Techniques and Equipment Commons, Other Neuroscience and Neurobiology Commons, Other Psychiatry and Psychology Commons, Rehabilitation and Therapy Commons, and the Sports Sciences Commons

This Article is brought to you for free and open access by the Brain, Biology and Behavior, Center for at DigitalCommons@University of Nebraska - Lincoln. It has been accepted for inclusion in Center for Brain, Biology and Behavior: Papers \& Publications by an authorized administrator of DigitalCommons@University of Nebraska Lincoln. 


\title{
Validating Tackle Mechanics in American Football: Improving Safety and Performance
}

\author{
Arthur Maerlender, ${ }^{1}$ Caitlin J. Masterson, ${ }^{2,3}$ \\ Rex Norris, ${ }^{4}$ and Adam Hinthorne ${ }^{4}$
}

\begin{abstract}
1 Center for Brain, Biology and Behavior, University of Nebraska-Lincoln, East Stadium, UNL, Lincoln, NE 68588, USA

2 People Data Clarity, LLC, Springfield, MO, USA

3 Department of Psychology, University of Central Arkansas, Conway, USA

4 Atavus Football Performance Company, Seattle, WA, USA

Correspondence - Arthur Maerlender, Center for Brain, Biology and Behavior, University of Nebraska-Lincoln, East Stadium, UNL, Lincoln, NE 68588, USA;

email amaerlender2@unl.edu

ORCID Arthur Maerlender http://orcid.org/oooo-ooo1-9740-6354
\end{abstract}

\begin{abstract}
Research has helped to understand the risks of injuries of tackling in American football and rugby; however, approaches to teaching and analysis are not well-documented. Shoulder-led tackling has been proposed as a safer approach to tackling even though data on the effectiveness for safety and defensive performance is limited. Additionally, some have argued that safety and effectiveness are incompatible. The purpose of the study was to validate a specific sequence of tackling actions as a tool for teaching safer and more effective tackling skills. Results suggested tackle scores help predict presence of head contact, and that higher tackle scores were associated with reductions in Yards After Contact (YAC). Eight hundred and thirty-two
\end{abstract}

Published in Annals of Biomedical Engineering (2020)

doi:10.1007/s10439-020-02625-7

Copyright (c) 2020 Biomedical Engineering Society; published by Springer. Used by permission.

Submitted 25 August 2020; accepted 16 September 2020; published 30 September 2020. 
(832) American high school football tackles were rated using a 12- element rating system. Estimated Structural Equation Modeling (ESEM) was employed to identify the factor structure of the elements with three factors identified: Track, Engage, and Finish. ANOVA, along with logistic and linear equation models were run to determine relationships between tackle scores and outcomes. Tackle scores predicted head-contact category (binary logistic regression accuracy $=.76$ ). Yards after contact (YAC) were significantly reduced [Finish factor: $\operatorname{MANOVA~} F(3,828)=105.825$, $p<.001]$. Construct and predictive validity were demonstrated and show that these tackle elements provide valid foci for teaching better tackling as well as analyzing both teaching effectiveness and performance.

Keywords: Concussion prevention, Tackle kinematics, American football, Head impact exposure (HIE), Defensive performance

\section{Introduction}

Head impact exposure (HIE) is the proximate cause of concussion and mild traumatic brain injury (mTBI). ${ }^{21}$ Although individual impacts of high magnitude have been related to concussions, some researchers feel that the cumulative amount of HIE can cause concussions and may be a factor in more distant problems such as neurodegenerative disease. ${ }^{3,18,22,28}$ Head contact in tackling often results in the highest magnitude of HIE, 1,9,16,25 and it is believed that recurring biomechanical force is linked to neurologic disease, most recently chronic traumatic encephalopathy (CTE).4,12,14

Tackling or being tackled has been recognized as the largest contributor to American football head injuries. ${ }^{2,23}$ According to Kontos et al., head to head contact was the most frequent cause of concussions in youth football players 8-12 years old. ${ }^{20}$ Further, Alois et al. documented higher head acceleration values on instrumented helmets when youth made head to head contact than the average of other head impact exposure values. ${ }^{1}$

Tackling in American football is inherently risky. Several initiatives have begun to address the concerns about HIE in American football tackling. USA football has adopted a shoulder-led tackling program with some success. ${ }^{19,29}$

Empirical approaches to tackle analysis have primarily been made in rugby 15,26,27 and Rugby League. ${ }^{10}$ Burger et al. developed a laboratory protocol for analyzing rugby tackles that included nine tackle elements across pre-contact, contact, and post contact phases of tackling. 
Video analysis of body position in tackling was compared between live tackle rating and the use of a mechanical tackling simulator. Interrater reliability of coding their system was good; rating tackles on the mechanical simulator was comparable to ratings of live tackles. ${ }^{8} \mathrm{Re}-$ cently Stockwell et al. identified use of the "inside shoulder" versus "head across the body" was more effective in terms of tackles made in middle school and youth leagues. ${ }^{24}$

This study utilized behavioral video-based ratings of tackles in high school games that were part of tackle-training education evaluation. The tackle elements were developed by a group of rugby and football coaches and players who worked with the Seattle Seahawks to implement a "shoulder-led" tackling method typically taught in rugby. ${ }^{11}$

It was hypothesized that the construct validity of the tackle sequence would be demonstrated through factor analysis while the predictive validity would be verified by demonstrating that higher scale values would reflect behaviors associated with less head contact and better defensive performance (fewer YAC).

Hypothesis I: Confirmatory factor analysis using exploratory structural equations modeling (ESEM) would reveal a factor structure reflecting tracking behaviors and contact behaviors.

Hypothesis II: Higher levels of skill-mechanics (as indexed by higher tackle-rating scores) would be associated with no head-contact in tackles, whereas tackles with head-contact would have significantly lower tackle-rating scores.

Hypothesis III: Better skill-mechanics, as indexed by higher tacklerating scores, would predict fewer yards gained by the ball-carrier after contact with the tackler (yards after contact or YAC).

\section{Materials and methods}

\section{Procedure}

\section{Rationale and Description of the Tackle Sequence}

The sequences specified were first defined proscriptively based on experts' opinions of proper tackle mechanics. Five elite athletes and coaches from football and rugby were convened to define the sequence of skill-mechanics in order to teach this method to players. Based on 
reviews of the kinematic features of tackles, a system of rating using specific criteria for each element and outcome was developed, manualized, and implemented. This rating system includes 12 discrete and sequential behaviors that are rated from the time the ball is snapped to the end of the play.

The four elements in tracking are primarily actions based on visual-motor responses with the person alone in space (fending off a block is an exception). Thus, tracking is more dependent on speed of reaction, visual identification, and tracking than on biomechanical actions in contact.

In the engagement or contact phase, the elements specified are somewhat arbitrary points in the kinematic sequence as some happen at the same time. The elements are described as having a proper base of support (Base), the near foot up (Power Step), a relatively straight spine and neck (Spine), shoulder pads lowered to aim at midsection above hips (Pad Level), making initial contact with near shoulder (Near Shoulder) to help maintain linear kinetic energy from the near foot, driving the near arm forward (Punch), wrapping with both arms for control of the ball carrier (Wrap), and continuing to drive forward to complete the tackle (Leg Drive). Figure 1 presents visual graphics of the Contact and Finish elements.

From a biomechanical perspective, the first four elements help to establish stability and prepare the body for generating linear kinetic energy. The base should be shoulder width, and the "power step" has the near foot closest to the ball carrier. While this reduces stability somewhat (if a force comes at the tackler in a direction off-axis with his stance), when the ball carrier makes contact with the near shoulder, the stability is increased and the body position provides a more direct path for the kinetic energy into the ball carrier. Thus, stepping into a ball carrier with the near foot and making contact aligns the force causing the center of gravity (CG) and this second point of contact to provide a more stable impact because the body is aligned with any imposing force.

Spine and Pad Level are highly related and together lower the center of gravity (increasing stability). The combination of Spine, Pad Level, Power Step and Near Shoulder maintain alignment with the direction of force so that the linear distance to imposing forces, and thus the rotational moment, across the spine and neck are minimized. 
Validating Tackle Mechanics in American Football

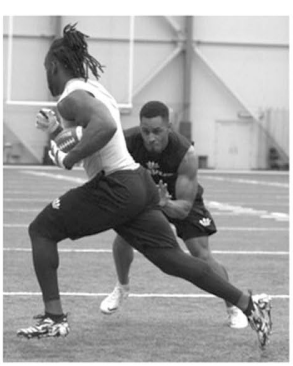

Pad Level

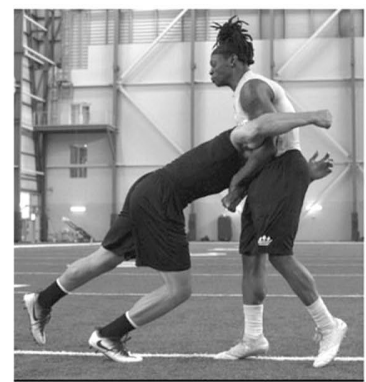

Punch

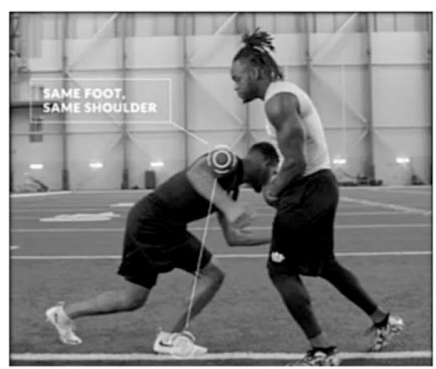

Base, Power Step

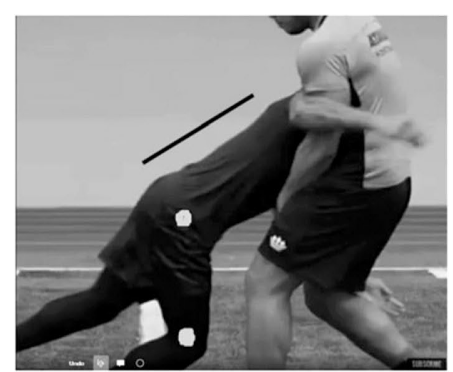

Spine, Shoulder

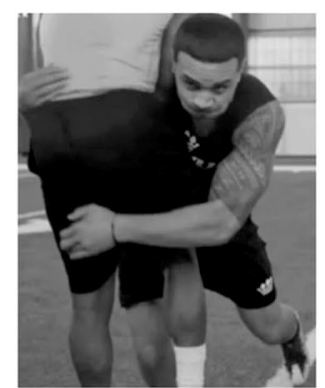

Wrap

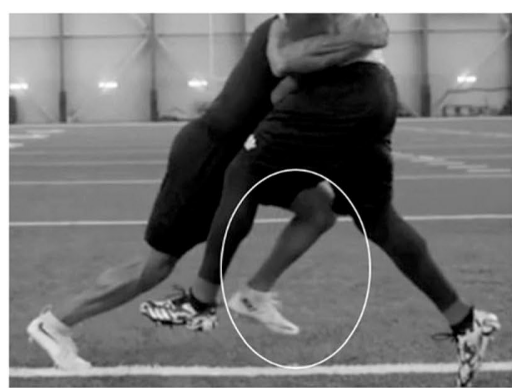

Leg Drive

Figure 1. Pictorial examples of the sequence of tackle elements for the two contact factors used in rating tackles.

The Punch is a rapid movement of the inside/contact shoulder and arm, just as contact is being made, similar to a "punching action" that attempts to fully grasp and wrap the arm around the ball carrier. This coincides with the opposing arm that also is reaching around the ball carrier to fully control and "wrap" the ball carrier with both arms. The Wrap is the successful action of both arms "wrapping" around the ball carrier, providing body control and body engagement to minimize movement of the ball carrier.

Importantly, Gellner et al. ${ }^{16}$ demonstrated that youth tacklers instrumented with helmet-mounted accelerometer arrays experienced reduced high magnitude head impacts when in a hips- and knees-bent body position, and primary contact was made with the shoulder or arm. These positions are consistent with Pad Level, Spine, and Near Shoulder.

When taken as a kinematic sequence, these positions and motions are intended to maximize stability and strength, body control, and power (kinetic energy), while also minimizing unnecessary head 
contacts and body-torque that would reduce energy and put the body at greater risk of injury. Indeed, the study by Stockwell noted the awkwardness of the cross-body tackle mechanics. ${ }^{24}$

\section{Tackle Event Selection}

The data were collected as part of coach education programs that utilize video analysis for assessment and instruction. No personally identifiable information was recorded for this analysis.

The original survey of video rated game-tackles contained 8041 tackles in the years 2017-2018 (17 teams across 10 weeks of play). To reduce ambiguity and provide the most characteristic tackle mechanics, both good and bad, the following reductions were used. Tackles in pass coverage were removed $(n=163)$, leaving 7878 tackles. From this set, only positive tackles were retained $(n=2364)$. Missed tackles (i.e., being in position to tackle but making no contact), tackle situations with only arm contact below the elbow, and tackles with YAC greater than 20 yards were eliminated (totaling 1338). These categories overlapped some. After this process, the pool of tackles was 1026. The matching procedure reduced the final sample to 832 cases for analysis (see Table $\mathbf{1}$ for matching characteristics).

Positive tackles occur when the ball-carrier is in front of the tackler as the tackler is facing the line of scrimmage. While there are a smaller portion of overall tackles, the negative situation tackles do not utilize the full sequence of tackle elements because the ball carrier is running away from the tackler: leg drive is either impossible or counter-productive (e.g., by driving the ball carrier towards their goal line: see Fig. 2). The reliability of rating this tackle situation variable is reported in Table $\mathbf{2}$.

Table 1. Head contact by playing position.

\begin{tabular}{lcccc} 
& \multicolumn{3}{c}{ HC type } \\
\cline { 2 - 4 } Position & Head contact & Helmet to helmet & No head contact & Total \\
\hline DB & 153 & 65 & 218 & 436 \\
DL & 29 & 27 & 56 & 112 \\
LB & 77 & 65 & 142 & 284 \\
Total & 259 & 157 & 416 & 832 \\
\hline
\end{tabular}

DB defensive back, DL defensive line, LB linebacker. 


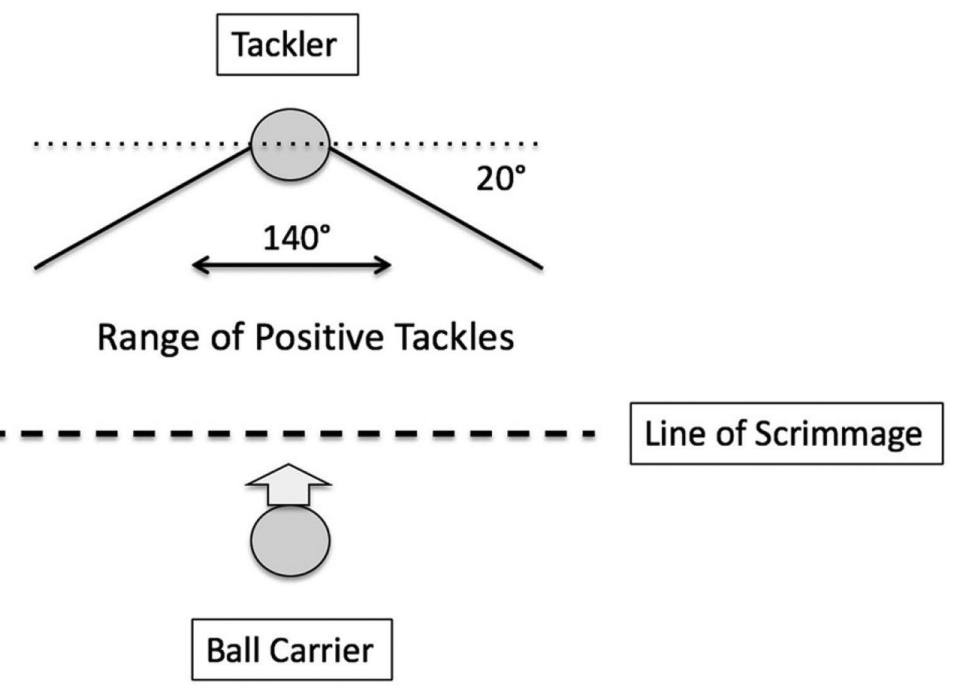

Figure 2. Schematic of positive tackle.

Table 2. Standardized factor loading estimates.

\begin{tabular}{lccc} 
& 1: Track & 3: Finish \\
\hline $\begin{array}{l}\text { Element } \\
\text { Pursuit }\end{array}$ & $0.65^{1}$ & & \\
Reaction & $0.96^{1}$ & 0.37 & \\
Angle & $0.96^{1}$ & & \\
Near hip & $0.96^{1}$ & & \\
Base & 0.57 & $0.72^{2}$ & \\
Power step & 0.58 & $0.70^{2}$ & $\mathrm{~ns}$ \\
Pad level & $\mathrm{ns}$ & $\mathrm{ns}^{2}$ & $0.42^{3}$ \\
Spine in line & 0.40 & & \\
Shoulder & & $0.49^{2}$ & $0.89^{3}$ \\
Punch & & 0.51 & $0.98^{3}$ \\
Wrap & & & $0.56^{3}$ \\
Leg drive & & & \\
\hline
\end{tabular}

Superscripts denote the factor assigned for further analyses.

The tackle is a dynamic event in which multiple players can be involved while the ball-carrier is trying to avoid being tackled. Although some tackles involved only one player, tackle events involving the first 2 "responders" in the tackle were included. Later responders were not considered because the initial contacts limit the later tacklers' options and thus do not provide an opportunity to demonstrate the skills. 
Matching Procedure

Tackles were matched by position and amount of head-contact (HC). Table 1 demonstrates the result of matching position and $\mathrm{HC}$ type.

Video Rating, Reliability and Quality Control

Each game had a single film angle originating from the top of the stands on the sideline, which provided an aerial angle view that was as parallel to the line of the scrimmage as possible. Every clip showed all 22 players at the snap of the football, then the camera followed the ball carrier over the course of the play.

Inter-rater reliability by independent raters was previously shown to be excellent. The procedure used here involved two raters. In this exercise, each tackle was rated by a primary rater then confirmed by a second rater to assure agreement of ratings.

\section{Measures}

\section{Tackle Ratings}

In general, the process for developing behavioral criteria involves selection of the behaviors, specification of the rating items (item development), development of the scale (including factor extraction), and scale evaluation (reliability and validity). ${ }^{5}$ In order to develop a consistent and standard approach to instruction, this analysis adopted a behavioral rating system to assess the degree of adherence to specific skill implementation. Although multiple approaches to developing a rating system are feasible,${ }^{6}$ a checklist approach was used for speed and efficiency: for each defined tackle element, raters were asked to rate whether or not each behavior was exhibited, based on a manualized set of criteria. The sums of elements within each factor could then be used to analyze the outcomes, and in practice are used to point to team and individual strengths and weaknesses.

\section{Safety Outcome: Head-Contact}

For assessing safety, the outcome variable was the frequency of categories of head-contact in tackles. The three head-contact categories were: no head-contact, head to body contact, and head to head contact. However, for most analyses, head to head contact and head to body 
contact were combined and compared to no head-contact (HCyn). Note that head to ground impacts can also cause injury but are not typically caused by the tackle mechanics, and usually happen to the ball carrier, not the tackler.

\section{Performance Outcome: Yards After Contact (YAC)}

The performance outcome was the amount of YAC. YAC is an estimated measurement based on the yard markers on the video. The validity of YAC as a defensive statistic has been shown in a separate dataset of 172 high school games where YAC was calculated for each tackle. The relationship between total YAC for the game and points allowed in those games revealed a large effect: $R^{2}=3.26, t=9.063, p<.001$.

\section{Independent Variables: Tackle Elements}

In the framework used here, the kinematic sequence of tackle behaviors begins with the snap of the ball and includes 12 discrete tackle behaviors or actions that are each operationally defined. It should be noted that this system (called Tacklytics ${ }^{\mathrm{TM}}$ ) includes tackler behaviors from the snap of the ball to the down; thus, it also assesses pre-engagement actions (called tracking). A checklist of each element was rated on a binary scale (present-absent). Scores for each factor were generated similar to the approach of Hendricks. ${ }^{17}$ If an element was blocked from sight but the preceding and succeeding elements were present, and all indications were that the target element was present, it was rated as present; otherwise it was rated as absent. The elements assess initial response to the ball in play, direction of approach and ability to change direction, targeting of the ball carrier, proper foot and body position going into engagement, use of proper shoulder and associated arm movements, maintaining physical contact through the tackle, and keeping momentum towards the defender's goal or sideline.

In order to identify key constructs across the 12 tackling elements, confirmatory factor analysis (exploratory structural equation modeling: ESEM) was employed. ESEM is an overarching integration of the

best aspects of exploratory and confirmatory factor analysis (EFA and CFA, respectively), as well as structural equation modeling (SEM). However, unlike overly restrictive EFA and CFA, ESEM assesses model fit by allowing each element to load onto multiple factors (Brown, 
2015). This model produced a 3-factor solution with excellent fit (see Results), factors are labeled Track, Engage, and Finish.

\section{Reliability of Ratings}

Previous analysis of unpublished (in-house) data has demonstrated excellent inter-rater reliability of all variables used here. Inter-rater reliability was assessed with intraclass correlations (ICC). In the first analysis, 10 tackles were randomly selected from a 100-tackle dataset from a professional team. Three raters independently rated the tackles. For these analyses the 12 elements were analyzed as two factors (six elements each): Track and Engage. A two-way random effects model with absolute scores was conducted. A second analysis assessed 16 player-tackles that were randomly selected from a set of Division-1 football games in the company's archive. The index team had been trained in this tackling method for two seasons. Three data analysts independently rated the video clips of the tackles and intraclass correlation coefficients (ICCs) were calculated (two-way random effects model). ICC's for tackle situation, YAC, head-contact, tracking and engagement were all above .836 .

\section{Analysis}

ESEM was conducted using Mplus version 7 (Muthén \& Muthén, 2012) with estimator WLSMV (mean and variable adjusted weighted least squares) for categorical data. Model fit was assessed using global fit indices chi-square $\left(\chi^{2}\right)$, comparative fit index (CFI), Tucker-Lewis index (TLI), and root mean squared error of approximation (RMSEA).

To assess the independence of the two outcome measures, an ANOVA was conducted (head-contact group by YAC).

A two-way MANOVA was used for the analysis of the two HC groups (no head contact, head contact with either head to head or head to body). Binary logistic regression was calculated to determine the predictive value of the full tackle sequence score on head contact (any head-contact, no head-contact: HCyn). Spearman's correlation was used to compare factor scores to HCyn status.

To determine their relationship with YAC, the factor scores were entered into a correlation matrix. Follow-up analysis with linear regression using a stepwise procedure was calculated using the tackle factors to predict YAC. The stepwise procedure was chosen due to 
potential correlation of the factors. Linear regression also was implemented with YAS as the dependent measure and the full tackle sequence score as the independent variable. Finally, to confirms the validity of YAC as a valid performance measure, linear regression of YAC predicting opponents' game scores were calculated.

\section{Results}

\section{Construct Validity: Factor Structure}

The first hypothesis was partially confirmed as tracking and contact were differentiated; however, a third factor emerged reflecting the end result of the tackle ("Finish").

The three-factor ESEM model produced excellent global fit $\left(\chi^{2}=\right.$ 46.17, $p=.06, \mathrm{CFI}=.99 \mathrm{TLI}=.98, \mathrm{RMSEA}=0.02(90 \% \mathrm{CI}[0.00$, 0.04]). All standardized estimates (factor loadings) exceeded 0.30, suggesting that each indicator was a salient measure of the corresponding latent variable(s) with only one element dropping out of the factor matrix (Pad Level: see Table 2 for standardized factor loadings). ${ }^{7}$ Additionally, the covariances between the three latent factors were non-significant (standardized coefficients: F1wF2 $=0.12 ; \mathrm{F} 1 \mathrm{wF} 3$ $=0.14 ; \mathrm{F} 2 \mathrm{WF} 3=-0.06)$. This simply means that three distinct and unrelated constructs were measured. The final model construction appears in Fig. 3 .

It should be noted that the factor structure did not mirror the element sequences perfectly. In calculating scores for the factors, the Pad element was included in factor two (Engage) although it did not load onto any factor for ESEM. Although Punch loaded significantly on both factors two and three, the strongest relationship was with factorthree (Finish) so it was included only with that factor.

\section{Outcome: Head-Contact}

Spearman correlations between HCyn categories and factors were significant with a larger effect for the Engage factor (Table 3).

There was a multivariate effect of factor score by HCyn group: $F$ (3, $828)=105.825, p<.001$. Between factor effects were significant for 


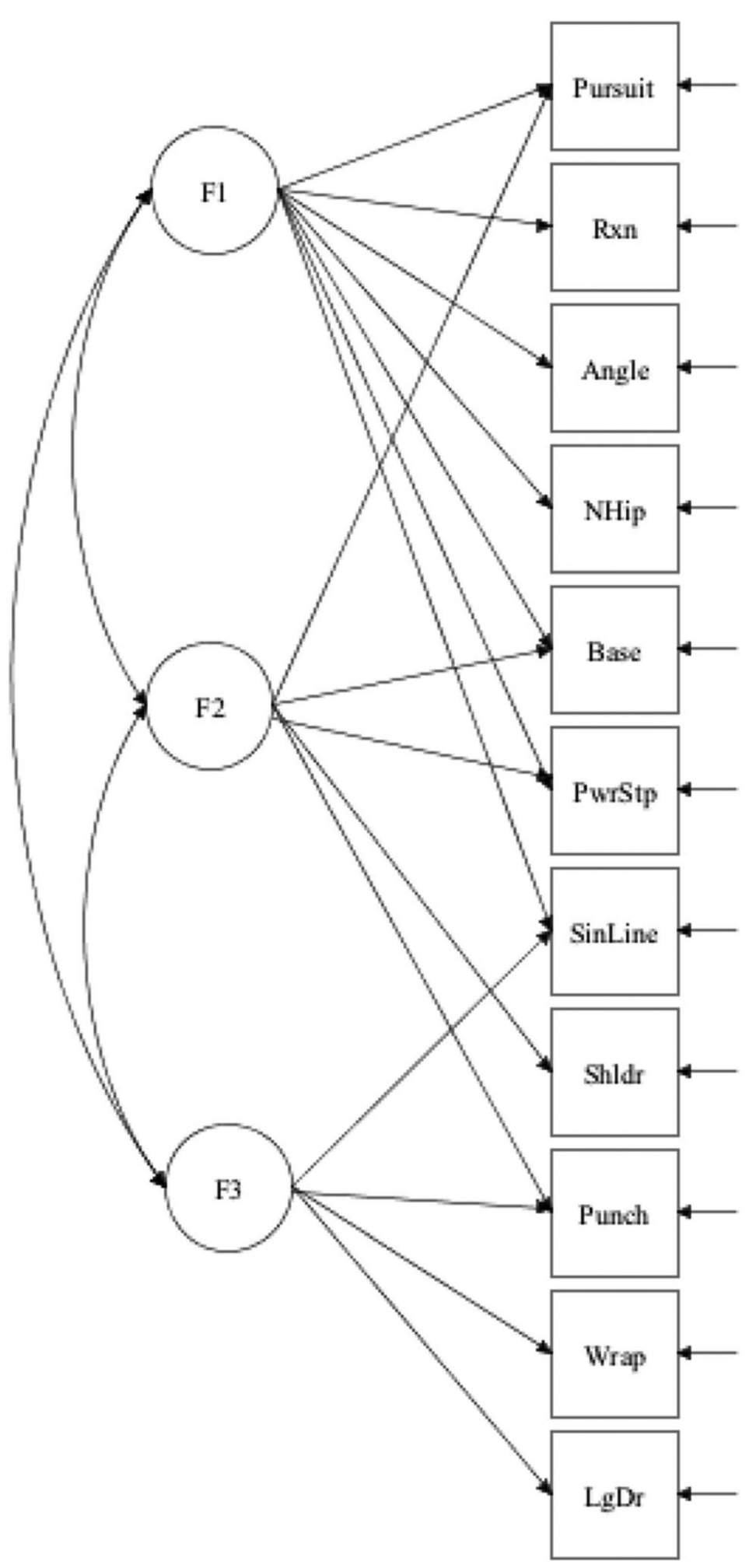

Figure 3. Formative ESEM model for 12 tackle elements. All factor loadings are positive. F1 track, F2 contact, F3 finish, Rxn reaction, NHip near hip, PwrStp power step, SinLine spine in line, Shldr shoulder, LgDr leg drive. 
Table 3. Correlation Matrix of Head-Contact (HCyn: Spearman's) and Yards After Contact (YAC: Pearson) with tackle element factors $(\mathrm{N}=832)$.

\begin{tabular}{lcccrrr} 
Variable & Statistic & YAC & HC $\left(r_{s}\right)$ & Track & Engage & Finish \\
\hline YAC & $r$ & \multirow{2}{*}{1} & -0.035 & -.070 & -0.058 & -.153 \\
& $p$ & & 0.31 & 0.045 & 0.095 & $<.001$ \\
\multirow{2}{*}{ HCyn } & $r_{s}$ & & 1 & .126 & .539 & .115 \\
& $p$ & & & $<.001$ & $<.001$ & 0.001 \\
\hline
\end{tabular}

Table 4. Between factor MANOVA results for HCyn groups $(\mathrm{N}=832)$.

\begin{tabular}{lrrr} 
Factors & $\mathrm{F}$ & $p$ value & $\eta_{p}{ }^{2}$ \\
\hline Track & 13.387 & $<.001$ & 0.016 \\
Engage & 304.873 & $<.001$ & 0.269 \\
Finish & 11.729 & .001 & 0.014 \\
\hline
\end{tabular}

$\eta_{p}{ }^{2}=$ partial eta squared.

all factors (Table 4). Note that the effect size for factor 2 was large, whereas effect sizes for factors 1 and 3 were small.

Binary logistic regression of HCyn with factor 2 (Engage) was significant: Wald $=181.648, p<.001$. The overall classification accuracy was 0.76 and for no head contact was 0.69. Receiver operator characteristics (ROC) found the area under the curve to be $0.78, p<.001$ $(95 \% \mathrm{CI}=0.752-0.782)$.

ESEM suggested only the second factor (Engage) significantly predicted the likelihood of HCyn, which was in a negative direction (unstandardized estimate $=-2.04, p=.002$ ). This is interpreted by examining the presence or absence of the tackle elements that make up the second factor. As the presence of those specific elements increases, the likelihood of head contact decreases.

\section{Outcome: YAC}

The relationship of YAC to the three factors was demonstrated in a correlation matrix. Pearson correlations found factor 3 (Finish) to have the strongest relationship with YAC followed by factor 1 (Track). Factor 2 (Engage) was not significantly related (see Table 4). The stepwise linear regression found only factor 3 accounting for significant 
variance in YAC $\left(R^{2}=0.023, t=24.450, p<.001\right)$. The full sequence of elements predicted a small but significant amount of variance in YAC scores: $R^{2}=0.025, t=24.626, p<.001$.

To confirm the validity of YAC as a performance outcome, the linear regression of YAC predicting opponents score was carried out. Results of the linear regression were significant: $R^{2}=0.021, t=4.252$, $p<$.001.

The confirmatory factor model (ESEM) demonstrated that the first and third factors (Track and Finish, respectively) significantly predicted change in YAC.. Both factors were related negatively to YAC (Track unstandardized estimate $=-0.53, p=.03$; Finish unstandardized estimate $=-0.33, p<.001$ ), indicating that as the presence of those specific elements increases, the number of yards gained after contact decreases. Model construction appears in Fig. 4.

\section{Relationship of Outcomes}

The outcome variables demonstrated no systematic relationship to each other and are thus independent indicators of outcome. An ANOVA of HCyn groups by YAC revealed a nonsignificant finding: $F(1,830)$ $=0.103, p=.748$.

\section{Discussion}

These analyses present results from video-based ratings of a tackle skill technique scoring system which relied on behavioral ratings of specific tackling elements in a particular sequence. The purpose of this approach was to provide a reliable structure for assessing tackleperformance and also to add structure to the teaching of tackling. In establishing the scale's validity, two outcome measures were chosen: head contact (the proximate "safety" goal of the skill sequence) and yards after contact (the more distal "performance" goal). Both hypotheses were confirmed and found to be significantly related to better skill performance.

Although elements and factors were differentially related to outcomes, results indicated that use of the full set of combined elements results in an increasing effect (correlation coefficients). Thus, teaching 


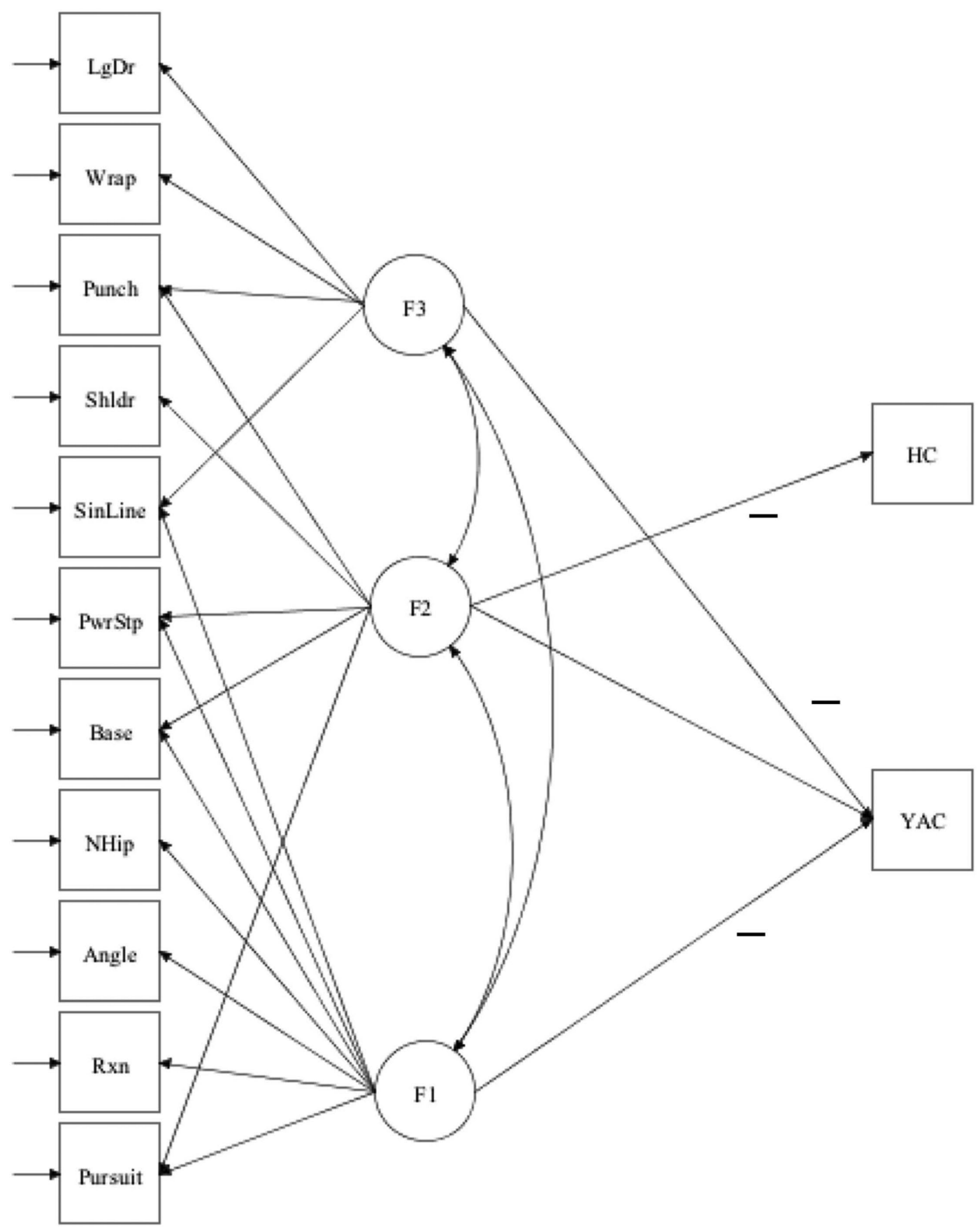

Figure 4. Formative ESEM and Path Model for Head Contact Group (HCyn) and Yards After Contact (YAC) predictions. F1 track factor, F2 contact factor, F3 finish factor, Rxn reaction, NHip near hip, PwrStp power step, SinLine spine in line, Shldr shoulder, LgDr leg drive. 
of the entire sequence is indicated, not just single elements or factors. Even though less head contact is logically safer, evidence of reduced YAC as an outcome of head-out tackling is also an important finding due to the relationship with team success.

The factor structure provided insights into performance that were consistent with expectations. In the regression analyses, factor 2 (Engage) was most strongly related to HCyn, whereas factor 3 (Finish) was significantly related to YAC. Effective tracking puts the player in position to make a proper tackle, but it is the skills in contact that are most important for limiting head contact. On the other hand, yards after contact are most impacted by the skills that follow Engage (factor 2).

Positional effects also were noted in tackle performance, with the defensive back position being associated with more YAC and lower tackle-scores for the Finish factor. Defensive backs have the furthest distance to cover and may be more impacted by defensive schemes.

Approximately half of the tackle events in the study sample were eliminated from analysis because technique and positioning were poor, or the player was "schemed" out of position to make a tackle. Additionally, because missed tackles result in no head contact, they provide no value in evaluating tackle technique. In practice, one might look at tracking to discover a cause for missing the tackle all together.

To date, the only study of American football to look at tackling outcomes related to safer tackling used the percent of completed tackles as the outcome, ${ }^{24}$ so a more informative metric was used for this study.

Due to suggestion that safety and performance in sport do not coexist, a secondary goal of this project was to determine if safety and performance were in fact, mutually exclusive. ${ }^{13}$ Corman's group carefully examined some of the socio-cultural aspects of sports that interfere with concussion education as well as athlete and coach responsiveness to concerns about concussions. They concluded that a firewall of sorts exists between performance and safety when it comes to knowledge, attitudes, and communication about concussions. This study hopes to break down that firewall by demonstrating that performance and safety are not separate, but supportive elements of each other.

There are several limitations to this study. As noted, some nonparametric analyses were required based on the use of categorical data. 
Although such checklist data is frequently used, it limited the questions that could be asked. A second limitation is the lack of base rate data. All of the tackles analyzed here came from schools with some level of knowledge and exposure to this coaching system. Some may criticize the use of positive tackles only, which was done to take advantage of the full tackle sequence; however, subsequent analyses will address this limitation. Additionally, the researchers are not independent as they are consultants and employees of the company marketing this method.

American football has lagged behind rugby in terms of specific skill technique development and analyses. The current concerns over safety and concussions is providing impetus to address this lack. Overall, the findings of reduced head contact using shoulder-led tackling are consistent with studies in rugby. Davidow found better tackle technique by rugby players was associated with fewer instances of head contact. ${ }^{15}$ This group also has provided a framework for implementing the teaching (coaching) of proper techniques ${ }^{17}$; however, use of behavioral ratings to assess and monitor learning were not described.

This analysis is unique in several ways. First, the sequence of elements described provides a valid framework for the coaching of tackling. Few studies define tackle situations and thus insert random variance into their analyses; by controlling for the tackle situation these findings are not hampered by such variation. Although not reported here, similar results have been obtained by adjusting the element factors to account for negative situation tackles. By analyzing the full set of behaviors from snap to down, this analysis captures information that is helpful in coaching and teaching beyond just the body in contact. Further, this analysis provides a means for analyzing individual and team behaviors and thus informs coaching on multiple levels. Finally, by demonstrating a positive effect for both safety and performance outcomes, the concerns about safety limiting performance can be put to rest.

Acknowledgments The authors would like to acknowledge Ryan Gellner, M.S. for his helpful comments on biomechanics. For assistance with graphics and images we acknowledge Michael Maerlender and Scott Lawson for their assistance and insights. Thank you to Atavus for access to their Tacklytics ${ }^{\mathrm{TM}}$ database. Photographs were used by permission of the subjects. 
Conflict of interest The first author (AM) is a consultant to Atavus but received no compensation for the preparation of this manuscript and has no other conflicts of interest. The third and fourth authors ( $\mathrm{RN}, \mathrm{AH}$ ) were employees of Atavus at the time of manuscript preparation. The second author (CM) has no relationship with Atavus and no conflicts of interest.

\section{References}

1 Alois, J., S. Bellamkonda, E. Campolettano, et al. Do American youth football players intentionally use their heads for high-magnitude impacts? Am. J. Sports Med. 47(14):3498-3504, 2019. https://doi.org/10.1177/0363546519882034

2 Badgeley, M., N. McIlvain, E. Yard, S. Fields, and R. Comstock. Epidemiology of 10,00o high school football injuries: patterns of injury by position played. $J$. Phys. Act. Health 10(2):160-169, 2013.

3 Bahrami, N., D. Sharma, S. Rosenthal, et al. Subconcussive head impact exposure and white matter tract changes over a single season of youth football. Radiology 281(3):919-926, 2016. https://doi.org/10.1148/radiol.2016160564

4 Baugh, C. M., C. A. Robbins, R. A. Stern, and A. C. McKee. Current understanding of chronic traumatic encephalopathy. Curr. Treat. Options Neurol. 2014. https://doi.org/10.1007/s11940-014-0306-5

5 Boateng, G. O., T. B. Neilands, E. A. Frongillo, H. R. Melgar-Quiñonez, and S. L. Young. Best practices for developing and validating scales for health, social, and behavioral research: a primer. Front. Public Health 2018. https://doi. org/10.3389/fpubh.2018.00149

6 Borman, W. C. Behavior-based rating scales. In: Performance Assessment: Methods and Applications, edited by R. Berk. Baltimore: The Johns Hopkins Press, 1986, pp. 100-120.

7 Brown, T. A. Confirmatory Factor Analysis for Applied Research. New York: The Guilford Press, 2015.

8 Burger, N., M. I. Lambert, H. Hall, and S. Hendricks. Assessing tackle performance using a novel collision sport simulator in comparison to a "live" one-on-one tackling drill. J. Sports Sci. 37(1):74-81, 2019. https://doi.org/10.10 80/02640414.2018.1482590

9 Campolettano, E. T., R. A. Gellner, and S. Rowson. High magnitude head impact exposure in youth football. J. Neurosurg. Pediatr. 20(6):604-612, 2017. https:// doi.org/10.3171/2017.5.PEDS17185

10 Carey, L., P. Stanwell, D. P. Terry, et al. Verifying head impacts recorded by a wearable sensor using video footage in rugby league: a preliminary study. Sports Med. Open 2019. https://doi.org/10.1186/s40798-019-0182-3

11 Carroll, P. Seahawks Head Coach Pete Carroll teaches rugby tackling. Published online July 29, 2014. Accessed June 9, 2019. https://www.youtube.com/ watch? $=7$ HihjPApzCg 
12 Churchill, N., M. Hutchison, D. Richards, G. Leung, S. Graham, and T. A. Schweizer. Brain structure and function associated with a history of sport concussion: a multimodal magnetic resonance imaging study. J. Neurotrauma 34(4):765-771, 2017. https://doi.org/10.1089/neu.2016.4531

13 Corman, S. R., B. J. Adame, J.-Y. Tsai, et al. Socioecological influences on concussion reporting by NCAA Division 1 athletes in high-risk sports. PLoS ONE. 14(5):eo215424, 2019. https://doi.org/10.1371/journal.pone.0215424

14 Costanza, A., K. Weber, S. Gandy, et al. Review: contact sport-related chronic traumatic encephalopathy in the elderly: clinical expression and structural substrates. Neuropathol. Appl. Neurobiol. 37(6):570-584, 2011. https://doi. org/10.1111/j.1365-2990.2011.01186.X

15 Davidow, D., K. Quarrie, W. Viljoen, et al. Tackle technique of rugby union players during head impact tackles compared to injury free tackles. J. Sci. Med. Sport 21(10):1025-1031, 2018. https://doi.org/10.1016/j.jsams.2018.04.003

16 Gellner, R. A., E. T. Campolettano, and S. Rowson. Does tackling form affect head acceleration in youth football players? Proc. Inst. Mech. Eng. Part P J. Sports Eng. Technol. 234(3):257-267, 2020. https://doi. org/10.1177/1754337120911497

17 Hendricks, S., K. Till, J. L. Oliver, et al. Technical skill training framework and skill load measurements for the rugby union tackle. Strength Cond J. 40(5):4459, 2018. https://doi.org/10.1519/SSC.0000000000000400

18 Horstemeyer, M. F., P. R. Berthelson, J. Moore, A. K. Persons, A. Dobbins, and R. K. Prabhu. A mechanical brain damage framework used to model abnormal brain tau protein accumulations of national football league players. Ann. Biomed. Eng. 47(9):1873-1888, 2019. https://doi.org/10.1007/ S10439-019-02294-1

19 Kerr, Z. Y., E. Kroshus, J. G. L. Lee, S. W. Yeargin, and T. P. Dompier. Coaches’ implementation of the USA football "Heads Up Football” educational program. Health Promot. Pract. 19(2):184-193, 2018. https://doi. org/10.1177/1524839917700398

20 Kontos, A. P., R. J. Elbin, V. C. Fazio-Sumrock, et al. Incidence of sportsrelated concussion among youth football players aged 8-12 years. J. Pediatr. 163(3):717-720, 2013. https://doi.org/10.1016/j.jpeds.2013.04.011

21 McCrory, P., W. Meeuwisse, J. Dvořák, et al. Consensus statement on concussion in sport-the $5^{\text {th }}$ international conference on concussion in sport held in Berlin, October 2016. Br. J. Sports Med. 51(11):838-847, 2017. https://doi. org/10.1136/bjsports-2017-097699

22 Montenigro, P. H., M. Alosco, B. M. Martin, et al. Cumulative head impact exposure predicts later-life depression, apathy, executive dysfunction, and cognitive impairment in former high school and college football players. $J$. Neurotrauma 34:328-340, 2016.

23 Shankar, P. R., S. K. Fields, C. L. Collins, R. W. Dick, and R. D. Comstock. Epidemiology of high school and collegiate football injuries in the United States, 2005-2006. Am. J. Sports Med. 35(8):1295-1303, 2007. https://doi. org/10.1177/0363546507299745 
24 Stockwell, D. W., R. Blalock, K. Podell, and R. A. W. Marco. At-risk tackling techniques in American football. Orthop. J. Sports Med., 2020. https://doi. org/10.1177/2325967120902714

25 Tucker, R. Decision-making and technique: evidence for increased head injury risk during tackling in rugby union. Br. J. Sports Med. 51(4):398-399, 2017. https://doi.org/10.1136/bjsports-2016-097372.291

26 Tucker, R., M. Raftery, G. W. Fuller, B. Hester, S. Kemp, and M. J. Cross. A video analysis of head injuries satisfying the criteria for a head injury assessment in professional Rugby Union: a prospective cohort study. Br. J. Sports Med. 2017. https://doi.org/10.1136/bjsports-2017-097883

27 Tucker, R., M. Raftery, S. Kemp, et al. Risk factors for head injury events in professional rugby union: a video analysis of 464 head injury events to inform proposed injury prevention strategies. Br. J. Sports Med. 51(15):1152- 1157, 2017. https://doi.org/10.1136/bjsports-2017-097895

28 Urban, J. E., E. M. Davenport, A. J. Golman, et al. Head impact exposure in youth football: high school ages 14 to 18 years and cumulative impact analysis. Ann. Biomed. Eng. 41(12):2474-2487, 2013. https://doi.org/10.1007/ s10439-013-0861-Z

29 USA Football. Heads up Football. USA Football, 2017. 